\author{
INMACULADA MURCIA SERRANO \\ UNIVERSIDAD DE SEVILLA
}

\title{
De Dios y lo sublime
}

\begin{abstract}
egún afirma el teólogo protestante Rudolf Otto en su obra Lo santo. Sobre lo racional e irracional en la idea de Dios, ${ }^{\mathrm{I}}$ el sentimiento que produce en el hombre lo numinoso, pese a lo difícil que resulta describirlo, se puede caracterizar como ambivalente, pues por un lado humilla y anega, pero por otro encumbra y exalta. Es principalmente esta convicción la que lo conduce a afirmar que existe una correspondencia, aunque lejana y difícil, entre lo sublime y lo numinoso:
\end{abstract}

Esta armonía de contraste que intentamos, aunque no podemos, describir puede ser sugerida, bien que remotamente, por una analogía sacada, no de la misma esfera religiosa, sino de la estética. Cierto que es un pálido reflejo, y además también de análisis muy difícil. Nos referimos a la categoría y al sentimiento de lo sublime. ${ }^{2}$

Antes de la aparición de la estética como disciplina autónoma al margen de la religión, esta comparación podía resultar razonable, puesto que el concepto de lo sublime, que fue estableciéndose como categoría estética, retórica o poética en el marco de la teoría clasicista de los estilos gracias a la fama cosechada por el texto del pseudo Longino, pasó a la retórica latina y a la Edad Media con cierta relación con las ideas cristianas de la divinidad, que persistieron incluso en el romanticismo. ${ }^{3}$ Durante 17 siglos la reflexión estética convivió, de hecho, confundida con la ética y con la moral religiosa. Sin embargo, a partir

I. Rudolf Otto, Lo santo. Sobre lo racional e irracional en la idea de Dios, I9I7, Fernando Vela (trad.), Madrid, Alianza, I998.

2. Ibidem, p. 67.

3. Pedro Aullón de Haro, "La categoría de lo sublime", en Friedrich Schiller, Lo sublime (de lo sublime y sobre lo sublime), José Luis del Barco (trad.), Málaga, Ágora, I992. El término sublime se reincorpora al vocabulario estético cuando Boileau traduce el Tratado de lo sublime de Longino en I694. 
del siglo XVIII dicha reflexión se independiza y nace entonces una nueva disciplina desasida, cada vez más, de esos dos ámbitos de especulación. De ahí que resulte por lo menos curioso que en pleno siglo xx Rudolf Otto recupere de nuevo la correspondencia. En una nota a pie de página, y "rizando el rizo", el teólogo afirma que el sentimiento religioso no constituye en realidad un sentimiento estético. En todo caso, lo sublime (hýpsos, en alemán das Erhabene) sugiere —como un "pálido reflejo"- el sentimiento indescriptible que produce en el hombre lo numinoso, categoría irracional extraída de la religión. Aunque las esferas estética y religiosa son distintas, añade, esos dos sentimientos parecen presentar analogías, lo cual le permite explicar, aunque por reflejo, algo tan indescriptible como la experiencia humana del numen o Dios.

La comparación a la que Otto somete estos dos términos - lo numinoso y lo sublime - se basa en las explicaciones que del segundo formula Immanuel Kant en la Kritik der Urteilskraft (Crítica del juicio). ${ }^{4}$ Lo que pretendo en este artículo es analizar en qué grado es procedente dicha comparación y si efectivamente lo sublime de Kant puede o no sugerir, en cierto modo, la experiencia inenarrable de lo religioso. ${ }^{5}$

\section{Lo numinoso y lo sublime}

Según Otto, lo santo (das Heilige), término al cual está dedicado el libro, constituye una categoría explicativa y valorativa que como tal se presenta y nace exclusivamente en la esfera religiosa. Se trata de una categoría compleja, entre cuyos componentes se encuentra un elemento específico y singular que se sustrae a la razón y que es inefable (árreton), es decir, imposible de conceptualizar. Para explicar en qué consiste este extraño componente, Otto se hace eco del uso popular que posee el término "santo" como bondad perfecta o suma, sentido que también le asigna Kant cuando llama "santa" a la voluntad. Pero a ello añade - y esto es importante— que, aunque este sentido primero sea cierto, lo santo contiene un "excedente" de significación para nombrar, el cual

4. Immanuel Kant, Crítica del juicio, Manuel García Morante (trad.), Madrid, Espasa Calpe, I999.

5. Profundizo, pues, en una cuestión que ha sido señalada por Richard White en su artículo "The Sublime and the Other", The Heythrop Journal, Oxford/Boston, Blackwell Publisher, 38 (2), I997, pp. I25-I 43, artículo en el que indaga de forma más general la relación a que nos conduce lo sublime con la otredad, fundamentalmente con la que constituye de por sí lo sagrado. 
carece de un término. Al teólogo se le hace necesario inventar una palabra que designe "lo santo menos su componente moral" y "menos cualquier otro componente racional". ${ }^{6}$ Otto está interesado en indagar, e incluso en nombrar por primera vez, ese excedente significativo que contiene la categoría racional de lo santo, aquella que, según él, vive en todas las religiones como su "fondo" y "médula", y que no tiene nada que ver con la moral ni con cualquier otro componente racional de la religión. El neologismo que propone es el de lo numinoso (das Numinose) que, como lo santo, constituye también una categoría explicativa y valorativa, pero sobre todo - y esto es lo que nos interesa- una disposición o temple del ánimo.

Otto utiliza constantemente terminología kantiana para referirse tanto a lo santo como a lo numinoso: los considera a ambos categorías puras y a priori y lo hace porque quiere defenderse contra cualquier sensualismo y evolucionismo en materia religiosa, de manera que dichos términos, categoriales en sentido kantiano, sean considerados innatos en el hombre. Sólo así puede sostener que existe un instinto religioso en el ser humano. ${ }^{7}$ Ello explica las alusiones recogidas en su libro a la Crítica de la razón pura, ${ }^{8}$ especialmente al llamado "giro copernicano", según el cual hay una parte del conocimiento que es trascendental y la "pone" el sujeto, y otra que proviene de la experiencia y es a posteriori: de la misma manera, lo numinoso pertenecería a esa clase de conocimientos que nuestra propia facultad intelectual proporciona, empero no instigada por las impresiones sensibles. Como el propio autor explica: "Irrumpe de la base cognoscitiva más honda del alma, pero no antes de poseer datos y experiencias cósmicas y sensibles, sino en éstas y entre éstas. Pero no nace de ellas, sino merced a ellas". ${ }^{9}$ Es como si determinadas experiencias sensibles dieran ocasión para que el sujeto sintiese en su interior lo numinoso, un sentimiento que se encuentra dentro de él, pero que requiere una motivación externa para manifestarse. Lo numinoso aludiría, pues, como los conceptos puros del entendimien-

6. Otto, op. cit., p. I5.

7. Hay que tener en cuenta que la filosofía de la religión de Rudolf Otto concuerda con la de Kant y suele incluirse en la llamada escuela neofriseana. Pero Otto, como Max Scheler, aplica el método fenomenológico para delimitar la esencia de la religión. Toda fenomenología religiosa, según Ismael Quiles, parte de la idea de que existe una esfera de objetos y de valores específicamente religiosos que, además de su ser específico, mantienen una conexión esencial con el hombre o, mejor aún, son esenciales para él (Filosofía de la religión, Madrid, Espasa Calpe, 1973).

8. Immanuel Kant, Critica de la razón pura, Pedro Ribas (trad. y notas), Madrid, Alfaguara, I998.

9. Otto, op. cit., p. 156. 
to y las valoraciones e ideas estéticas y morales de Kant, a una fuente oculta y sustantiva de representaciones y sentimientos al margen de la experiencia sensible; para Otto, señalaría a una "razón pura" en el sentido más profundo, pero, según el autor, y quedémonos con esta diferencia, una razón muy distinta a la kantiana, puesto que, "por el carácter superlativo de sus contenidos, ha de diferenciarse también de la razón pura teorética o práctica de Kant como algo que es más elevado o profundo que ella”. ${ }^{\text {ro }}$ Para Otto existe, en definitiva, un instinto o sentimiento religioso, una razón profunda inserta en el alma pero superior, sin embargo, a la razón teórica y práctica kantiana. Esta diferencia es importante porque servirá de fundamento para criticar la relación que existe, según este autor, entre lo numinoso y lo sublime.

Refiere Otto, además, que esa lejana correspondencia es fácil de entender y se fundamenta en varias cuestiones: en primer lugar, en que lo sublime kantiano constituye un concepto que no se puede desarrollar y, en segundo, en que, contrariamente, de él se pueden reunir tan sólo algunas notas, entre las que cuentan la saturación a que son sometidos los límites de nuestra facultad de comprensión y la amenaza que se sigue de sobrepasarlos "dinámica" o "matemáticamente". I I Otto precisa que "esta nota no es, evidentemente, más que una condición, no la verdadera esencia de la impresión sublime”. I2 Señala, en este sentido, que una simple magnitud no es sublime por grande que sea. De ahí deduce que en el concepto de lo sublime hay algo de misterio, igual que en el de lo numinoso. Lo que le parece indiscutible es que ambas experiencias colman los límites de nuestra facultad de comprensión y amenazan con sobrepasarlos, mientras que al mismo tiempo operan sobre el ánimo una doble impresión a la vez retrayente y atrayente.

Aunque éstas son las principales comparaciones que Otto establece entre lo numinoso y lo sublime a lo largo de su libro, sugiere algunas más. Una de ellas es la sospecha de que la conexión entre ambos radica en algo más que en una simple asociación de sentimientos, pues lo sublime podría considerarse en realidad un verdadero "esquema" —en sentido kantiano- de lo santo. Otto asegura a continuación que lo sublime se presenta en los estadios más elevados de la religiosidad como medio de expresión que sustituye a lo horrible:

\section{Io. Ibidem, p. I57.}

II. Recordemos que, según Kant, hay dos tipos de sublimidad: lo sublime matemático, provocado por un objeto de magnitud tal que impide la síntesis de la imaginación, y lo sublime dinámico, causado por la fuerza incontrolable de la naturaleza.

I2. Otto, op. cit., p. 68. 
A medida que va siendo superado lo horrible, se hace más fuerte y estable la conexión de lo santo con lo sublime y su esquematización por éste, hasta el punto de que esta esquematización se conserva como legítima aun en las formas más elevadas del sentimiento religioso. Buena prueba de que entre lo numinoso y sublime existe una oculta afinidad y correspondencia, lo cual es algo más que una mera semejanza fortuita. Kant hace una breve referencia a esto en su Critica del juicio. ${ }^{13}$

Lo sublime, según Otto, sería el resultado de una especie de evolución con respecto al sentimiento más primitivo de lo horrible, que, una vez que se alcanza, serviría incluso de "esquema", en sentido kantiano, de lo santo. Según el autor esto está sugerido en la tercera crítica kantiana.

\section{En qué no se parecen lo sublime y lo numinoso}

La primera tesis de Otto, según la cual lo sublime — como lo numinoso- llena los límites de la comprensión y amenaza con sobrepasarlos, deriva efectivamente de la "Analítica de lo sublime", aunque en esta parte de la Crítica del juicio ese carácter posee implicaciones teóricas que Otto no tiene en consideración. Nos encontramos, para empezar, ante una de las diferencias que Kant establece entre lo bello y lo sublime. Pese a que entre estos dos sentimientos y juicios existen numerosas coincidencias, ${ }^{\mathrm{I} 4}$ las desavenencias se arrogan todo el protagonismo: en primer lugar, para Kant, lo bello de la naturaleza lo suscita la forma del objeto, su limitación; lo sublime, sin embargo, puede encontrarse en un objeto sin forma, en la ilimitación; lo bello, en segundo lugar, es exposición de un concepto indeterminado del entendimiento, mientras que lo sublime, por el contrario, lo es de un concepto indeterminado de la razón; en tercer lugar, lo bello produce una satisfacción unida a la cualidad; lo sublime, una satisfacción unida a la cantidad; en cuarto lugar, lo bello produce un sentimiento de impulsión a la vida porque la imaginación juega; lo sublime, sin embargo, excita un sentimiento de suspensión momentánea de las facultades además de un desbordamiento de ellas, de ahí que se hable de la "seriedad" (Ernst) de la ima-

13. Ibidem, p. 94 .

I4. Para Kant, lo bello y lo sublime coinciden en que placen por sí mismos, en que presuponen un juicio de reflexión y en que sus juicios son particulares, aunque universalmente valederos, si bien sólo remiten al sentimiento de placer y dolor y nunca al conocimiento del objeto. Véase Kant, Crítica del juicio, op. cit., p. 23. 
ginación; su placer es, en consecuencia, negativo y positivo, de manera que el espíritu resulta a un tiempo, y al contrario que respecto a lo bello, atraído y rechazado. ${ }^{\mathrm{I}} \mathrm{La}$ primera analogía que Otto pretende establecer, la que se refiere a la superación de las facultades de conocimiento, se apoya, pues, en la tesis kantiana de que, a diferencia de lo que ocurre durante la experiencia de lo bello, en la de lo sublime no existe acomodación del sujeto a la experiencia, lo cual impide que, en el juicio de gusto, se produzca el libre juego de las facultades de la imaginación y el entendimiento.

Recordemos, a este respecto, que el juicio de lo bello refiere efectivamente la imaginación, en su libre juego, al entendimiento, porque lo que se pretende es concordar con los conceptos de éste en general, aunque sin determinación de ellos. Por el contrario, lo sublime kantiano supera esa misma acomodación. Debido a la falta de juego entre dichas facultades, como ya había adelantado Kant en la obra precrítica dedicada a lo bello y lo sublime en I764, lo bello encanta mientras que lo sublime conmueve. ${ }^{\mathrm{I}}$ Para Kant, lo que se nos presenta desde el exterior suscitando el sentimiento de lo sublime es tan grande o tan potente que sobrepasa con creces nuestra facultad de aprehensión, tanto que lo sublime no puede ser en realidad, por paradójico que ello resulte, objeto de los sentidos. Pese a que hablamos normalmente de lo sublime para referirlo a los objetos de la naturaleza, Kant cree que al hacerlo cometemos un error: cuando se trata de la belleza natural, dice, es como si encontráramos en ella una finalidad formal mediante la cual el objeto parece estar determinado de antemano para nuestro juicio. Pero lo que despierta en nosotros el sentimiento de lo sublime es precisamente contrario a nuestro juicio, no traspasa la síntesis de la imaginación y, por lo tanto, no puede aplicarse a los objetos de la naturaleza (ni mucho menos a los del arte, determinados tanto en forma como en magnitud por un fin humano). Tan sólo puede proyectarse sobre la naturaleza misma en estado bruto. Sólo así es posible establecer un juicio estético puro, es decir, sin que se mezclen en él juicios teleológicos como juicios de razón. ${ }^{17}$ Por decirlo de otra manera, un juicio puro sobre lo sublime, para que sea

15. Idem.

I6. Immanuel Kant, Lo bello y lo sublime. La paz perpetua, Ángel Sánchez Rivero y Francisco Rivera Pastor (trads.), Buenos Aires, Espasa Calpe, 1946.

I7. "Me limito a observar que si el juicio estético ha de ser puro (sin mezcla de juicios teleológicos, como juicios de razón), y si con él debe darse un ejemplo totalmente adecuado a la crítica del juicio estético, hay que mostrar lo sublime, no en los productos del arte [...] sino en la naturaleza bruta." Kant, Critica del juicio, op. cit., p. 26. ("Bemerke nur, dass, wenn das ästhetische Urteil 
estético, no puede tener como fundamento de determinación fin alguno sobre el objeto y no debe confundirse, por consiguiente, con ningún juicio del entendimiento o de la razón. Por eso, para Kant, la sublimidad se encuentra fundamentalmente en el espíritu. Como él señala, si para lo bello de la naturaleza tenemos que buscar una base fuera de nosotros, para lo sublime, sin embargo, sólo debemos hacerlo dentro de nosotros. ${ }^{18} \mathrm{La}$ causa de que el sujeto experimente lo sublime no radica, en definitiva, en lo que recibe del exterior, que no es más que su ocasión, sino en nuestra propia imaginación, por un lado, que encierra una tendencia a progresar en lo infinito, y en nuestra propia razón, por otro, que paralelamente exhibe una pretensión de totalidad. Lo sublime, en suma, no constituye una cualidad de los objetos, sino, como lo numinoso de Otto, una disposición o temple del espíritu: "Ha de llamarse sublime, no el objeto, sino la disposición del espíritu, mediante una cierta representación que ocupa el Juicio reflexionante". ${ }^{19}$ Esa disposición del espíritu trasciende, pues, los sentidos: "Sublime es lo que, sólo porque se puede pensar, demuestra una facultad del espíritu que supera toda medida de los sentidos". ${ }^{20}$

Ahora bien, aunque lo sublime en Kant, como acierta a especificar el propio Otto, provoque un desbordamiento de nuestra facultad de comprensión —aunque se trate más de un sentimiento que de un objeto exterior-, el teólogo obvia que si lo hace es para dejar que surja otra facultad de tipo suprasensible y relacionada con las Ideas, aquellas que ya no conciernen al conocimiento —al

rein [mit keinem teleologischen als Vernunfturteile vermischt] und daran ein der Kritik der ästhetischen Urteilskraft völlig anpassendes Beispiel gegeben werden soll, man nicht das Erhabene an Kunstprodukten [...] sondern an der rohen Natur [...] aufzeigen müsse.” Immanuel Kant, Kritik der Urteilskraft, Hamburgo, Felix Meiner Verlag, 1990, p. 97.)

I8. "Para lo bello de la naturaleza tenemos que buscar una base fuera de nosotros; para lo sublime, empero, sólo en nosotros y en el modo de pensar que pone sublimidad en la representación de aquélla." Kant, Critica del juicio, op. cit., p. 23. " Zum Schönen der Natur müssen wir einen Grund ausser uns suchen, zum Erhabenen aber bloss in uns und der Denkungsart, die in die Vorstellung der ersteren Erhabenheit hineinbringt.” Kant, Kritik der Urteilskraft, op. cit., p. 90.)

19. Kant, Crítica del juicio, op. cit., p. 25. Véase asimismo p. 26: "Por esto se ve también que la verdadera sublimidad debe buscarse sólo en el espíritu del que juzga y no en el objeto de la naturaleza cuyo juicio ocasiona esa disposición de aquél”. ("Man sieht hieraus, dass die wahre Erhabenheit nur im Gemüte des Urteilenden, nicht in dem Naturobjekte, dessen Beurteilung diese Stimmung desselben veranlasst, müsse gesucht werden." Kant, Kritik der Urteilskraft, op. cit., p. IOI.)

20. Kant, Crítica del juicio, op. cit., p. 25. ("Erhabenen ist, was auch nur denken zu können ein Vermögen des Gemüts beweist, dass jeden Massstab der Sinne übertrifft.” Kant, Kritik der Urteilskraft, op. cit., p. 94.) 
entendimiento-, sino al pensar — la razón. Se trata de una facultad omitida en el juicio de lo bello y que, pese a ser la que en el plano del conocimiento postula la idea de Dios, no se menciona en la obra de Otto. Pero antes de valorar su importancia y su papel en la "Analítica de lo sublime", examinemos la base kantiana de otra de las analogías que existen, según este autor, entre lo sublime y lo numinoso.

Para Rudolf Otto, tanto lo uno como lo otro producen una doble emoción de carácter contrapuesto: humillan y abaten, pero, al mismo tiempo, encumbran y exaltan.

En efecto, como ya ha salido a relucir, en el examen que hace Kant del sentimiento de lo sublime se describen dos estadios de afección, uno negativo y otro positivo: en primer término, el sujeto de la experiencia aprehende algo grandioso (en el caso de lo sublime matemático, por ejemplo), muy superior a él en extensión material, y que es asistido por la sensación de lo informe, desordenado y caótico. La reacción inmediata es, en primer lugar, dolorosa: el sujeto se siente en un estado de suspensión ante ese objeto que le excede y sobrepasa. Lo experimenta, de hecho, como amenaza que se cierne sobre su integridad. A ello sigue, en segundo término, una reflexión sobre la propia insignificancia e impotencia del sujeto: el espíritu, refiere Kant, es movido (bewegt) en la representación de lo sublime, y "ese movimiento (principalmente en sus inicios) puede ser comparado con una conmoción, es decir, un movimiento alternativo, rápido, de atracción y repulsión de un mismo objeto". ${ }^{2 I}$

Esa primera consternación, según la cual el sujeto siente y reflexiona sobre su propia insignificancia, tiene mucho que ver - y seguramente ésta es la razón por la que aparece mencionado en el libro - con lo que Otto denomina "sentimiento de criatura" (das Kreaturgefühl), expresión que pretende corregir otra similar, el "sentimiento de dependencia" (Abhängigkeit), acuñada anteriormente por Friedrich D.E. Schleiermacher. Este autor, que influyó mucho en Otto, había intentado fijar en la Doctrina de la fe ${ }^{22}$ el punto de partida de toda religión en un especial sentimiento de dependencia o finitud que podría servir

2I. Kant, Crítica del juicio, op. cit., p. 27. ("Diese Bewegung kann [vornehmlich in ihrem Anfang] mit einer Erschütterung verglichen werde, d. i. mit einem schnellwechselnden Abstossen und Anziehen eben desselben Objetks." Kant, Kritik der Urteilskraft, op. cit., p. I03.) Véase también p. 27: "El espíritu se siente movido en la representación de lo sublime en la naturaleza, estando en contemplación reposada en el juicio estético sobre lo bello de la misma".

22. Friedrich D.E. Schleiermacher, Doctrina de la fe, I82 I-1822, en Werke, prefacio de August Dorner, Otto Braun y Johannes Bauer (eds.), Darmstadt, Scientia Verlag Aalen, 198I. 
para definir la relación fundamental que el hombre establece con Dios. Así, como Otto pretendió después, Schleiermacher convertía la religión en algo natural. ${ }^{23} \mathrm{Su}$ visión naturalista del sentimiento religioso influyó notablemente en Rudolf Otto, quien, como fenomenólogo de la religión, defendería en la misma estela la existencia de una esfera de objetos y valores específicamente religiosos y esenciales al hombre.

Sin embargo, Otto quería distanciarse de Schleiermacher en un aspecto: concretar, delimitar y describir en qué consiste particularmente tal sentimiento. Ésa es la razón por la que remplaza el "sentimiento de dependencia” por el de "criatura", una forma más exacta, según él, de señalar la conciencia humana de la finitud e indigencia humanas ante el numen tremendo. ${ }^{24} \mathrm{El}$ matiz de diferenciación que introduce respecto a la tesis de Schleiermacher radica en que dicho sentimiento no constituye, en realidad, un sentimiento de mí, sino, como él dice, un "momento concomitante, un efecto subjetivo", "la sombra de otro sentimiento, el cual, desde luego, y por modo inmediato, se refiere a un objeto fuera de mí". ${ }^{25}$ Otto quiere subrayar, frente a Schleiermacher, y más en consonancia con lo sublime de Kant, que el sentimiento religioso, pese a ser una emoción interior, es producido en el sujeto por algo externo, el numen, que actúa como su ocasión, y que consigue que el sujeto se sienta abatido o humillado. El sentimiento de criatura surgiría, en suma, a diferencia del sentimiento de dependencia, del contraste con esa potencia superior y externa, y se experimentaría, en última instancia, como sentimiento de la propia sumisión, del anonadamiento, del ser tierra, ceniza o nada, como lo expresa Otto.

En este primer momento de conmoción estética y religiosa negativa, lo sublime y lo numinoso parecen, pues, susceptibles de comparación, aunque Kant, como ya hemos visto y volveremos a verlo más adelante, no identifica

23. Ignacio Izuzquiza, Armonía y razón. La filosofía de Friedrich D.E. Scheleiermacher, Prensas Universitarias de Zaragoza, I998. En una obra anterior, el Discurso sobre la religión (I799), más conocido como Reden, Schleiermacher había definido el sentimiento religioso como "Staunendes Anschauen des Undendlichen" ("intuición asombrada de lo infinito") y, también, como "Sinn und Gechmack fürs Unendliche” ("sentido y gusto por lo infinito”). Después, en su segunda gran obra, La doctrina de la fe sustituyó el punto de partida de la religión, puramente intuitivo y relacionado con el gusto, por el del sentimiento.

24. Esta indigencia aparece también en muchos otros filósofos de la religión: el mismo Kant la contempla al considerar la necesidad de Dios y de la religión para sostener al hombre en la moral; Fries, en el mismo sentido de Schleiermacher, considera al hombre dependiente de Dios; también Bergson, Scheler y Boutroux. Véase Quiles, op. cit.

25. Otto, op. cit., p. 20. 
en exclusiva la causa externa que lo provoca con el numen. Además, en el sistema kantiano, este primer momento de emoción recibe una fundamentación teórica que es tergiversada en el libro de Otto y que tiene que ver con el conflicto de las facultades. ${ }^{26}$

Según Kant, lo sublime provoca esta primera consternación principalmente porque nos pone en presencia de una relación subjetiva directa, pero conflictiva, entre la imaginación y la razón: "El sentimiento de lo sublime es, pues, un sentimiento de dolor que nace de la inadecuación de la imaginación, en la apreciación estética de las magnitudes, con la apreciación mediante la razón”. ${ }^{27}$ Por eso, más que concordante, esa relación es en primer término discordante, de ahí el dolor. En palabras de Deleuze, se asiste a "una contradicción vivida entre la exigencia de la razón y la potencia de la imaginación”. ${ }^{28}$ Durante la experiencia de lo sublime, la imaginación parece perder su libertad, lo que torna el sentimiento en algo doloroso. Sólo como puntualización advirtamos que si hay algo parecido a esto en el libro de Otto, aunque con muchos matices, es su insistencia en el postulado de que lo numinoso, en tanto mysterium tremendum, traspasa los límites de nuestra razón, y por ello debe considerarse algo irracional:

No sólo las rebasa —dice—, no sólo las hace ineficaces, sino que, en ocasiones, parece ponerse en contraposición a ellas y derogarlas y desbaratarlas. Entonces este aspecto del numen, además de incomprensible, se convierte en paradójico; porque no está ya por encima de toda razón, sino que parece ir contra la razón. ${ }^{29}$

A diferencia de lo que ocurre con lo sublime, no es que lo numinoso coloque en apuros a la imaginación, sino que, para Otto, es tan misterioso y heterogéneo que en ningún sentido se puede conocer o imaginar. De ahí su carácter irracional y de ahí también el dolor que suscita en un primer estadio. Lo numinoso y lo sublime sobrepasan, pues, la facultad de comprensión provocando en el sujeto un sentimiento negativo.

26. Véase ibidem, p. I44.

27. Kant, Crítica del juicio, op. cit., p. 27. ("Das Gefühl des Erhabenen ist also ein Gefühl der Unlust, aus der Unangemessenheit der Einbildungskraft in der ästhetischen Grössenschätzung zu der Schätzung durch die Vernunft." Kant, Kritik der Urteilskraft, op. cit., p. I02.)

28. Gilles Deleuze, La filosofía crítica de Kant, Marco Aurelio Galmarini (trad.), Madrid, Cátedra, 1997, p. 91.

29. Otto, op. cit., p. 45. 
Sin embargo, hay que tener en cuenta, y esto es muy importante, que en el sistema kantiano el hecho de que lo sublime traspase los límites del entendimiento y de la imaginación no es motivo suficiente para considerarlo ajeno a la racionalidad. Todo lo contrario, gracias a la experiencia de lo sublime, el hombre accede a su condición de ser, no sólo sensible, sino racional y moral. Este importante salto que Kant introduce en la "Analítica de lo sublime" no es mencionado en absoluto por Otto, y por eso su interpretación resulta criticable a menos que consideremos que incurre en una confusión terminológica grave, pero aceptable, según la cual lo que él considera "razón" sería en Kant "entendimiento" y lo que para Kant es "racional" se equipararía en Otto con "irracional". Se trata de una salvedad demasiado generosa para tenerla realmente en consideración, de ahí que merezca más comentarios.

No deja de ser curioso, en primer lugar, que Otto acuda a Kant para explicar, aunque sea por analogía, el sentimiento que produce el numen en nosotros, cuando en realidad critica la postura kantiana ante la religión y especialmente su deseo de ubicarla "dentro de los límites de la pura razón". En una nota a pie de página de Lo santo. Sobre lo racional e irracional en la idea de Dios, Otto se refiere a este problema:

Estas formas [se refiere a las formas anormales y extravagantes en que pueden traducirse las emociones religiosas] pueden parecer enfadosas cuando se pretende construir "una religión dentro de los límites de la pura razón o de la humanidad"; pero cuando se pregunta qué es la religión no dentro de los límites trazados antes, sino tal como ella es en realidad, hemos de determinarla según la describimos. Este método, por el cual se presupone una humanidad a nuestro capricho, cercenándole al hombre las potencias más íntimas y propias, equivale al de quien construyera el concepto de un cuerpo normal después de haberle quitado la cabeza. ${ }^{30}$

Otto reprocha a Kant que extirpe de la religión los elementos irracionales, lo mismo que hace con William James, en cuya obra Las variedades de la experiencia religiosa encuentra una contradicción: que los testimonios religiosos que se recapitulan estén sembrados de elementos irracionales, mientras que, a la hora de analizar, sean radicalmente desechados. ${ }^{3 \mathrm{I}}$ Tanto en una como en otra

30. Ibidem, pp. 60-6I.

3I. El libro de William James, nacido de un curso impartido en las Gifforg Lectures de Edimburgo entre I901 y 1902, tiene como objetivo, igual que el del propio teólogo alemán, estudiar la 
críticas parece claro que lo importante estriba en resaltar el aspecto irracional de lo religioso, eludido, a sus ojos, en la obra de esos dos pensadores. Tal objetivo orienta el libro de Otto hacia derroteros completamente ajenos a los kantianos, y ello debe tenerse en consideración a la hora de analizar la influencia que sobre él ejerció el filósofo de Königsberg. Pero ello significa también, para lo que a nosotros nos importa en este momento, que, si se puede emparentar ese excedente significativo e irracional de lo santo con el sentimiento estético de lo sublime, entonces esta categoría estética — siempre a los ojos de Otto- debería contener ciertas cualidades distintas a las de la razón. La pregunta que debería contestarse para llevar a cabo esta crítica sería, pues, la siguiente: ¿supera lo sublime los límites de la racionalidad? Se trata de una cuestión interesante, porque su respuesta podría desautorizar el vínculo que aquí se establece entre lo numinoso y lo sublime.

En lo sublime kantiano, todo sucede como si la imaginación se enfrentara a su propio límite, como si sufriera una violencia que la conduce al término de su poder. Para entender cómo ocurre esto, es necesario distinguir entre las dos actividades características de la imaginación, la receptiva y la pasiva: en tanto la imaginación trata de aprehender (aprehensión sucesiva de las partes), no tiene límite. Pero cuando intenta reproducir las partes precedentes a medida que llega a las siguientes, se topa con un máximo de comprensión. ${ }^{32}$ Ante lo inmenso (lo sublime matemático), por ejemplo, la imaginación experimenta

"religión personal", concretamente los "feelings, acts and experiences of individual men in their solitude" ("los sentimientos, los actos y las experiencias de hombres particulares en soledad"). Pero, a diferencia de Otto, la religión personal, para James, sí es susceptible de estudio, aunque no teológico. El filósofo defiende esta idea porque está convencido de que, cuando se pretende utilizar el término "sentimiento religioso" como enunciado colectivo para todos los sentimientos que los objetos religiosos provocan, se comprueba que no contienen psicológicamente nada que sea de una naturaleza específica: existe, por ejemplo, el temor religioso, el amor religioso, el miedo religioso, etc., pero, para este filósofo, el temor religioso no es más que el temor ordinario; el amor religioso, el amor humano dirigido a un objeto religioso, etc. Esa convicción lo conduce a afirmar, en clara oposición a Otto, que "con los estados de ánimo concretos, constituidos por un sentimiento más un tipo específico de objetos, las emociones religiosas son obviamente entidades psíquicas diferenciables de otras emociones concretas, pero no fundamento cierto para suponer que una simple 'emoción religiosa' abstracta exista por sí misma como una afección mental elemental distinta, patente en cada experiencia religiosa sin excepción”. William James, Las variedades de la experiencia religiosa. Estudio de la naturaleza humana, J.F. Yvars (trad.), Barcelona, Península, 2002, p. 57. James niega, en suma, la existencia de una esfera de sentimientos estrictamente religiosa al margen de la que tenemos normalmente en la vida ordinaria.

32. Deleuze, op. cit., p. 90. Véase también Kant, Crítica del juicio, op. cit., p. 26. 
la insuficiencia de dicho máximo. En un primer momento, según la interpretación de Deleuze, atribuimos esa inmensidad al objeto natural, a la naturaleza sensible, pero lo que realmente ocurre es que la imaginación se percata de que la razón es la única que, al impulsarla al límite de su poder, la "fuerza", por decirlo así, a confesar su impotencia. ${ }^{33}$ Ante la experiencia de lo sublime, la razón muestra a la imaginación que, por muy al infinito que tienda, sólo ella podrá alcanzar su Idea. Por eso, si en el juicio de lo bello, la imaginación está referida al entendimiento para concordar con sus conceptos de manera general, a través del libre juego de las facultades, en el aprecio de una cosa como sublime esa misma facultad se dirige hacia la razón para concordar, esta vez, con sus Ideas. Es justamente a partir de este momento cuando lo que comenzó siendo un sentimiento de dolor se torna placentero: en el fondo de esa discordancia, según la expresión de Deleuze, aparece la concordancia, porque, como afirma Kant, la presentación del infinito, aunque negativa, ensancha el alma, y ésta, entonces, se siente como una unidad suprasensible e indeterminada respecto a todas las facultades. Lo sublime, dicho ahora en palabras de Kant, "es la relación en la cual lo sensible, en la representación de la naturaleza, es juzgado como propio para un posible uso suprasensible del mismo". ${ }^{34}$

Debemos ya tener en cuenta que el interés que mueve a Kant en la "Analítica de lo sublime" rebasa lo estético para alcanzar lo moral, lo cual quiere decir que con lo sublime traspasamos el "desinterés" estético y entramos en el terreno de la voluntad. ${ }^{35}$ De hecho, Kant asegura que el sentimiento de lo sublime es engendrado en nosotros para disponernos hacia una finalidad más alta: el advenimiento de la ley moral. Por eso, esa angustia y ese vértigo dolorosos que experimenta el sujeto en un primer momento son finalmente combatidos por una reflexión segunda y placentera mediante la cual el sujeto se alza sobre su propia superioridad moral y racional. Es eso lo que ha conducido a Félix Duque a señalar que, así como la belleza nos hace ser y sentir por vez primera hombres al firmarse las paces entre la naturaleza y nuestro conocimiento, el sentimiento de lo sublime nos propone para un destino más alto: el de seres

33. Deleuze, op. cit., p. 91.

34. Kant, Crítica del juicio, op. cit., "Nota general a la exposición de los juicios estéticos reflexionantes", p. 212. ("Das Erhabene besteht bloss in der Relation, worin das Sinnliche in der Vorstellung der Natur für einem möglichen übersinnslichen Gebrauch desselben als tauglich beurteilt wird", Kant, Kritik der Urteilskraft, op. cit., p. I I3.)

35. Ernst Cassirer, Kant, vida y doctrina, Wenceslao Roces (trad.), México, Fondo de Cultura Económica, 1993, capítulo dedicado a la Crítica del juicio, pp. 318-420. 
justamente racionales. El conflicto que lo sublime ocasiona entre las facultades de la imaginación y el entendimiento — añade Duque a lo anterior — no hace otra cosa que mostrarnos que la razón está por encima de dichas facultades, que estamos en el mundo para renegar del mundo, $y$, en el ser, para alzar sobre éste el deber ser. ${ }^{36}$ No por casualidad en la "Analítica de la sublime" el filósofo de Königsberg parece identificar este sentimiento, en principio estético, con el ético del respeto (Achtung) hacia la ley moral: "El sentimiento de la inadecuación de nuestra capacidad para la consecución de una idea, que es para nosotros ley, es el respeto". ${ }^{37}$ Ese respeto, sacado a la superficie por lo sublime, no se proyecta hacia la naturaleza, sino hacia la ley, que la naturaleza nos hace sufrir, en todo caso, en sentido contrario. ${ }^{38}$ Posiblemente ésta es también la razón por la que el sentimiento de respeto hacia la ley moral es descrito por Kant, en la Critica de la razón práctica, en términos parecidos a los que utiliza para hablar de lo sublime en la Crítica del juicio, especialmente en lo que concierne a la ambivalencia de sentimientos positivos y negativos que ocasiona: en la segunda de las críticas se afirma, por ejemplo, que comprendemos a priori cómo la ley moral, en tanto fundamento de determinación de la voluntad, produce en nosotros un sentimiento doloroso porque causa perjurio a todas nuestras inclinaciones: por ejemplo, infiere daño a la estimación de uno mismo, a la presunción (Eigendünkel). Pero a eso añade Kant:

como esa ley, sin embargo, es en sí algo positivo, a saber, la forma de una causalidad intelectual, es decir, de la libertad, resulta que al debilitar la presunción oponiéndose a la resistencia subjetiva, a saber, a las inclinaciones en nosotros, es al mismo tiempo un objeto de respeto (Achtung), y el demostrarla completamente, es decir, humillándola, es un objeto del sumo respeto, y, por lo tanto, también el fundamento de un sentimiento positivo, que no es de origen empírico y que es conocido a priori. ${ }^{39}$

36. Félix Duque, Historia de la filosofía moderna. La era de la crítica, Madrid, Akal, I998, t. 8. 37. Kant, Critica del juicio, op. cit., p. 27. ("Das Gefühl der Unangemessenheit unseres Vermögens zur Erreichung einer Idee, die für uns Gesetz ist, ist Achtung." Kant, Kritik der Urteilskraft, op. cit., p. I02.)

38. Duque, op. cit.

39. Y agrega también: "Así, pues, el respeto hacia la ley moral es un sentimiento que está producido por un fundamento intelectual, y ese sentimiento es el único que nosotros podemos conocer enteramente a priori y cuya necesidad podemos penetrar”. Immanuel Kant, Critica de la razón práctica, Emilio Miñana y Villagrasa y Manuel García Morente (trads.), Salamanca, Sígueme, 1997, "Prólogo", p. 97. 
Como lo sublime, la ley moral humilla al hombre porque éste compara con ella las tendencias sensibles de su naturaleza. Pero, en un segundo estadio, aquello que nos humilla despierta, en cuanto es positivo y fundamento de determinación, respeto, tornándose entonces positivo y placentero.

Si esto es así, entonces nos encontramos muy lejos de lo que afirma Otto, puesto que, a partir de este salto de la estética a la moral, resulta imprescindible incluir en la "Analítica de lo sublime" no sólo la facultad racional, eliminada radicalmente por Otto en su acercamiento a los aspectos irracionales de la religión, sino también el elemento más importante del sistema kantiano: la libertad. ${ }^{40}$ Este concepto, como Idea de la razón, goza de privilegios respecto a las demás Ideas porque nos permite penetrar en el mundo inteligible, ${ }^{4 I}$ y ocurre así porque, según una de las famosas escisiones kantianas, el hombre pertenece a dos mundos, el sensual y el intelectual, y, aunque no puede renegar de ninguno de ellos, sí puede y debe subordinar el primero al segundo como campo de actuación de éste. ${ }^{42}$ Sólo en el suprasensible es posible la libertad, que constituye la base para cualquier fin moral. ${ }^{43}$ Lo sublime despierta en nosotros justamente esta idea, porque lleva a término la tensión hacia lo incondicionado que se impulsa durante el uso especulativo de la razón. Desde

40. Su preeminencia queda claramente establecida en la siguiente cita extraída de la Crítica de la razón práctica: "El concepto de libertad, en la medida en que su realidad (Realität) viene probada por una ley apodíctica de la razón práctica, constituye entonces la piedra angular del entero edificio de un sistema de la razón pura, incluso de la especulativa, y todos los demás conceptos (los de Dios y la inmortalidad) que, en cuanto meras ideas, permanecen sin sostén en aquélla, quedan anexionados ahora a él y con él y por él adquieren consistencia y realidad objetiva, es decir, la posibilidad de los mismos viene probada por el hecho de que hay efectivamente libertad, pues esta idea se manifiesta a través de la ley moral". Ibidem, p. 35 .

4I. "Por tanto, el concepto de la libertad (como concepto fundamental de todas las leyes incondicionales prácticas) puede ensanchar la razón por encima de aquellos límites dentro de los cuales todo concepto (teórico) de la naturaleza debía permanecer encerrado sin esperanza." Kant, Crítica del juicio, op. cit., p. 91. ("Mithin der Freiheitsbegriff [als Grundbegriff aller unbedingt-praktischen Gesetze] die Vernunft über diejenigen Grenzen erweitern kann, innerhalb deren jeder Naturbregriff [theoretischer] ohne Hoffnung eingeschränkt bleiben müsste.” Kant, Kritik der Urteilskraft, op. cit., p. 349.) Véase también el prefacio de la Crítica de la razón práctica y Deleuze, op. cit., p. 59.

42. Duque, op. cit.

43. No por casualidad la expresión "lo sublime" (das Erhabene) está etimológicamente ligada al término "elevación” (die Erhebung). Chevalier Jancourt, en su artículo "Sublime”, ibidem, p. I I 5 , dice que "es todo lo que nos eleva por encima de lo que éramos, y que al mismo tiempo nos hace sentir esta elevación” (siglo XVIII). 
ahí se entiende que, como ha dicho Félix Duque, "sentimos (lo sublime) para sabernos superiores a lo sentido". 44 Aunque en la filosofía de Kant todavía no esté rotundamente establecida esta correspondencia entre libertad y sublimidad, su hijo intelectual más cercano, Friedrich von Schiller, ya lo asentará con fuerza y sin disimulos:

Llamamos sublime al objeto cuya representación pone de manifiesto los límites de nuestra condición sensible y, a la par, la superioridad de nuestra naturaleza racional, y su independencia de toda constricción. Así pues, podemos elevarnos moralmente - es decir, mediante las ideas - sobre lo que físicamente nos coloca en situación de inferioridad. Sólo somos dependientes como seres sensibles. En cambio, como seres racionales somos libres. 45

En suma, en la estética kantiana no se puede pensar el sentimiento de lo sublime sin enlazar con él una disposición del espíritu semejante a la disposición racional hacia lo moral.

Todo ello nos conduce a valorar lo que establece Rudolf Otto en su obra, para aclarar, en la medida de lo posible, los errores o distorsiones a que somete el texto de Kant. Parece evidente que este autor se equivoca cuando elude hablar de que el sentimiento gozoso, y no ya terrible, de lo sublime tiene un carácter moral y, por ende, racional; también parece claro que se equivoca al desestimar la importancia de ello en la filosofía kantiana. Su interés es estrictamente religioso, no moral, y, mediante estas correspondencias entre lo numinoso y lo sublime, lo que pretende es dotar de una base filosófica sólida al sentimiento inenarrable de lo religioso. Otto convierte en irracional lo que en Kant es racional; elimina radicalmente la cuestión del conflicto de las facultades y sus implicaciones éticas; hace suyo el carácter contradictorio —doloroso y placentero- de este sentimiento pero llevándolo a su terreno, restringiéndolo al efecto subjetivo que ocasiona y eliminando, por ende, su fundamentación epistemológica; finalmente, pretende asimilar, aunque entre comillas, un sentimiento estético con otro que es exclusivamente religioso. En

44. Ibidem, p. II I.

45. Schiller, op. cit., p. 73. Se puede rastrear esta relación entre la experiencia de lo sublime y el sentimiento que acarrea cierta liberación incluso en la obra de Edmund Burke. Así lo ha entendido Diego Romero de Solís: "Esta experiencia estética supera las fronteras de lo finito, experimentando el sujeto en esa ruptura no su aniquilación sino una especie de exaltación, de liberación. El sujeto siente su propia infinitud", (La impaciencia del deseo, Sevilla, Alfar, I991, p. Ior). 
efecto, después de este análisis, el sentimiento de lo sublime debe considerarse un "pálido reflejo", cada vez más exangüe, de lo numinoso, al menos si tenemos en cuenta hasta sus últimos detalles lo que establece Kant. La principal crítica que podemos lanzar contra su libro es que, en la Crítica del juicio, lo sublime se conecta directamente con la moralidad y, por tanto, con la capacidad racional, mientras que, en la obra de Otto, lo sublime-numinoso atañe a la religión y, además, a sus aspectos meramente irracionales. El fenomenólogo de la religión se queda, por decirlo así, con una parte de la cuestión, pero sólo con una: que en el sentimiento de lo sublime, al abatimiento y la humillación les sigue una emoción positiva placentera. Decir esto sin profundizar en los detalles es tomar la parte por el todo y dejar a un lado lo que en verdad preocupaba a Kant: la moral, que en absoluto es en su sistema - dejémoslo solamente apuntado— irracional.

\section{En qué si se parecen lo sublime y lo numinoso}

Toda esta analítica no impide que podamos hacer justicia a Otto y aceptar en ciertos aspectos su conflictiva analogía. Pensemos que una de las Ideas de razón en la filosofía kantiana es la de Dios y que con ella se relaciona en efecto la idea de infinito y el sentimiento de lo sublime que ocasiona, aunque, como acabamos de ver, no sea ésta su única implicación.

Históricamente, el concepto de lo infinito posee un estrecho nexo con la religión, aunque para que tal vínculo se estableciese hubo de superarse la mentalidad griega que consideraba lo infinito como algo imperfecto. Se deberá a la teología judeocristiana la valoración positiva de lo infinito gracias a la cual, durante el siglo XvıII, producirá placer y terror estéticos al recibir por extensión el nombre de lo sublime. ${ }^{46}$ Será también ésta la razón ideológica que permitirá a muchos autores de la historia de la estética equiparar lo sublime con Dios. Esa identificación se encuentra, por ejemplo, en los que podemos considerar respectivamente como el precedente y el descendiente más directos de Kant: Edmund Burke y Friedrich von Schiller. Pero, antes de examinar lo que estos autores afirman al respecto, conviene repasar brevemente la relación que ha existido tradicionalmente entre lo terrible y lo sublime, una relación que Otto

46. Una breve aproximación a este desarrollo conceptual se encuentra en Eugenio Trías, Lo bello y lo siniestro, Barcelona, Ariel, 200I, p. 30. 
menciona en su obra para exponer la primera consternación provocada por el numen tremendo y que es imprescindible conocer antes de adentrarnos en la descripción de la experiencia —ahora sí — sublime de Dios. El teólogo se hace eco, en realidad, de una historia compleja que durante mucho tiempo asoció y disoció lo sublime y lo terrible y en la que los mismos Burke, Kant y Schiller, entre otros autores, tuvieron mucho que decir.

Según Pedro Aullón de Haro, en la evolución histórica de la categoría de lo sublime (pasando por alto el texto del pseudo Longino, en el que dicha cualidad se asigna todavía al más elevado de los estilos literarios) ${ }^{47}$ se pueden distinguir tres etapas y tres maneras de concebirla: el empirismo inglés (Addison-Burke), el idealismo alemán (Kant/Schiller-Schopenhauer) y una tercera etapa que transcurriría desde Lipps y Hartmann a la actualidad. ${ }^{48}$ Esta última la dejamos de lado porque no parece conferir un protagonismo especial a lo sublime, que sólo recuperan, curiosamente, los autores de la posmodernidad. 49 En el idealismo alemán, salvo en el caso de Kant, se tiende a hacer converger lo bello y lo sublime, y no a separarlos. Schelling y Solger, por ejemplo, lo conciben así porque consideran que la belleza consiste en la unidad de lo infinito y lo finito, por lo cual erradican toda oposición entre la belleza de la forma finita y la evocación de lo infinito que tiene lugar durante la experiencia de lo sublime. Para estos autores, los rasgos originarios de lo sublime están ya presentes en la belleza. En Inglaterra, sin embargo, el concepto de lo sublime sigue desempeñando — por ejemplo en Wordsworth, Burke y Coleridge— un papel autónomo y dialéctico respecto a lo bello, y es así como, en el caso del primero de ellos, lo bello se relaciona con el amor y la gentileza, mientras que lo sublime postula la excitación y el terror. ${ }^{50}$ Así pues, al menos en el pensamiento inglés, y como consecuencia de la nítida distinción establecida entre lo bello y lo sublime, éste parece estar conectado, en cierto modo, con el terror.

47. Para el pseudo Longino, lo sublime remite a la excelencia y perfección del discurso, el estilo noble o elevado. Considera que hay cinco causas para su surgimiento: la capacidad para concebir elementos elevados, la vehemencia o entusiasmo en lo patético o emocional, la forma de elaborar figuras del lenguaje, la nobleza de la dicción, la selección del vocabulario y el uso apropiado de la metáfora; finalmente, la composición integrada de palabras, ritmo y eufonía. Las dos primeras son una disposición o capacidad congénitas, mientras que las otras tres forman parte de la techné. Véase anónimo, Sobre lo sublime, José Alsina Clota (texto, introd. y trad.), Barcelona, Bosch, 1977.

48. Cfr. Aullón de Haro, "La categoría de lo sublime", en Schiller, op. cit.

49. Véase Frederic Jameson, Teorías de la postmodernidad, Madrid, Trotta, I990, y José Luis Brea, Las auras frías, Barcelona, Anagrama, I99I.

50. Paolo D’Angelo, La estética del romanticismo, Madrid, Visor, I999. 
Kant da un paso más, aunque sólo a partir de la etapa crítica. Todavía en el tratado precrítico sobre Lo bello y lo sublime, establece una clasificación de lo sublime en uno de cuyos estadios — lo sublime terrorifico — sigue teniendo cabida el terror. Una vez asentada la filosofía trascendental, esta clasificación desaparece, mientras que la relación entre lo sublime y lo terrorífico experimenta una transformación. En la tercera crítica, lo sublime representa, efectivamente, una evolución del sentimiento anterior de lo terrorífico, pero no se trata de una evolución histórica o ideológica, sino moral. Kant — como Schopenhauer señalará después-, cree que lo sublime se experimenta como terrorífico cuando el sujeto del padecimiento no ha desarrollado aún la capacidad cultural y moral. Pero cuando sí lo ha hecho ese aspecto desaparece. Eso quiere decir que el juicio kantiano sobre lo sublime requiere cultura, aunque Kant deja claro que no por eso es producido por la cultura e introducido convencionalmente en la sociedad, sino que tiene sus bases en la naturaleza humana y en lo que se puede exigir de cada cual, a saber, la disposición para el sentimiento de ideas prácticas, es decir, para la moral. Es justamente esta tesis la que proporciona un principio a priori a lo sublime afín a la filosofía trascendental. ${ }^{\text {II }}$ Tan exclusivo es este sentimiento, que Kant llega a afirmar que quien no lo experimenta carece de sentimiento alguno. ${ }^{52}$ Se aprecia, pues, cierto eli-

51. "Esta modalidad de los juicios estéticos, a saber, la necesidad que les es atribuida, constituye un momento principal para la Crítica del juicio, pues pendiente nos da justamente a conocer en ellos un principio a priori, y los saca de la psicología empírica, en donde permanecerían, sin eso, enterrados entre los sentimientos de alegría y pena (sólo con el epíteto de sentimientos más finos, que no dice nada), para ponerlos, y con ello el Juicio, en la clase de los que tienen por base principios a priori, y, como tales, elevarlos hasta la filosofía trascendental." Kant, Crítica del juicio, op. cit., p. 29. ("In dieser Modalität der ästhetischen Urteile, nämlich der angemassten Notwendigkeit derselben, liegt ein Hauptmoment für die Kritik der Urteilskraft. Denn die macht eben an ihnen ein Prinzip a priori kenntlich und hebt sie aus der empirischen Psychologie, in welcher sie sonst unter den Gefühlen des Vergnügens uns Schmerzes [nur mit dem nichtssagenden Beiwort eines feineren Gefühls] begraben bleiben würden, um sie und vermittelst ihrer die Urteilskraft in die Klasse derer zu stellen, welche Principien a priori zum Grunde haben, als solche aber sie in die Transzendentalphilosophie hinüberzuziehen.” Kant, Kritik der Urteilskraft, op. cit., pp. I I2-I I3.)

52. "En esto se funda ahora la necesidad de la concordancia del juicio de otros sobre lo sublime con el nuestro, lo cual atribuimos al mismo tiempo a éste, pues así como tachamos de falto de gusto a aquel que en el juicio de un objeto de la naturaleza encontrado bello por nosotros se muestra indiferente, de igual modo decimos del que permanece inmóvil ante lo que nosotros juzgamos como sublime que no tiene sentimiento alguno." Kant, Crítica del juicio, op. cit., p. 29. ("Hierauf gründet sich nun die Notwendigkeit der Beistimmung des Urteils anderer vom Erhabenen zu dem unsrigen, welche wir in diesem zugleich mit einschliessen. Denn so, wie wir dem, der in der 
tismo de tipo moral en lo que concierne al sentimiento de lo sublime, un elitismo que nos permite afirmar, con Otto, que lo sublime supone una especie de evolución, aunque no histórica, sino intelectual, respecto a la experiencia previa del terror.

Habría que recordar, en cualquier caso, que, según Kant, para experimentar, por ejemplo, lo sublime dinámico, la naturaleza tiene que ser representada como atemorizante, aunque ello no quiere decir necesariamente que el sentimiento que el sujeto padece sea el temor. El que teme - dice este filósofono puede en realidad juzgar sobre lo sublime de la naturaleza y no puede, por tanto, sentir su satisfacción. Es incapaz de hacerlo porque el sentimiento de lo sublime no se limita a producir en nosotros una conmoción, sino que, en el juicio estético, excita nuestra fuerza para considerar como pequeño aquello que nos preocupa (bien, salud, vida). La naturaleza, pese a ser representada como fuente de terror, consigue así "elevar" (erhaben, de donde procede el término sublime) la imaginación a la exposición de aquellos casos en los que el espíritu siente la propia sublimidad de su determinación, todo lo contrario que acontece cuando sentimos temor. ${ }^{53}$ Gracias a que, efectivamente, lo sublime representa un paso más respecto al terror, puede conducir al hombre a la moral y sólo eso puede hacerle sentir, en su completitud, el sentimiento cabal negativo y positivo de lo sublime.

Cuando Otto afirma que lo sublime es un desarrollo de lo terrorífico no lo está moviendo ningún interés moral, como le ocurre a Kant, aunque establece un paralelismo entre ese salto kantiano y el que él pretende asignar a lo religioso. En ambos casos, lo terrible se presenta como una especie de estadio primordial, pero superable, que conmociona el espíritu para ulteriormente catapultarse hacia la elevación. Sólo que en Kant esa elevación es de tipo moral y en Otto religiosa, lo que introduce enormes diferencias en sus aproximaciones. Lo que Otto quiere expresar es que el sentimiento religioso, el sentimiento que produce en el hombre el "numen tremendo", no se agota en el pavor que esa entidad abso-

Beurteilung eines Gegenstandes der Natur, welchem wir schön finden, gleichgültig ist, Mangel des Geschmacks vorwerfen, so sagen wir von dem, der bei dem, was wir erhaben zu sein urteilen, unbewegt bleibt, er habe kein Gefühl.” Kant, Kritik der Urteilskraft, op. cit., p. I I 2.)

53. "El que teme no puede en modo alguno juzgar sobre lo sublime de la naturaleza, así como el que es presa de la inclinación y del apetito no puede juzgar sobre lo bello." Kant, Crítica del juicio, op. cit., p. 28. ("Wer sich fürchtet, kann über das Erhabene der Natur gar nicht urteilen, so wenig als der, welcher durch Neigung und Appetit eingenommen ist, über das Schöne.” Kant, Kritik der Urteilskraft, op. cit., p. I06.) 
lutamente heterogénea, tremenda e incognoscible suscita. El sentimiento de lo numinoso va también más allá, como en Kant, resolviéndose en un sentimiento positivo que trasciende el dolor; pero si lo hace no es para desembocar en la moral ni para hacer sentir al hombre por encima de su insignificancia, sino para mostrar que Dios ocasiona no sólo temor, sino también una elevación del alma, una, para él, sublimidad del espíritu, de la cual sería signo la humildad religiosa.

Esta compleja relación entre el temor y la sublimidad, con todas las variantes a que ha dado lugar históricamente, constituye la base de las relaciones que Burke, Kant y Schiller establecieron entre lo sublime y Dios; por tanto, constituye también la base que impide concederle a Otto —al margen de las particularidades antes analizadas - la posibilidad de equiparar lo sublime con la experiencia irracional de lo religioso. Un breve repaso a sus ideas ilustrará el desarrollo histórico en el seno del cual se incluye la postura de Otto.

Es Edmund Burke el precursor a la hora de establecer analogías concretas entre el sentimiento de lo sublime y el de Dios y puede considerarse por eso el primer filósofo que sistematiza esta relación. Según se lee en su Indagación filosófica acerca de nuestras ideas sobre lo bello y lo sublime, cierta consideración de la Divinidad se empareja con el terror que acompaña al sentimiento de lo sublime. Para él —en esto recuerda mucho a Otto-, cuando consideramos a la Divinidad como un objeto del entendimiento, que forma una idea compleja de su poder, su sabiduría, su justicia y su bondad, la imaginación y las pasiones apenas se ven afectadas. Pero, puesto que estamos limitados por la condición de nuestra naturaleza a tener acceso a estas ideas a través de la imaginación, cuando nos representamos la Deidad formamos en verdad una especie de imagen sensible (¡el esquema al que se refiere Otto?) ${ }^{54}$ que sí es capaz de afectar sensiblemente a la imaginación. En concreto, es la imagen de su poder la que más nos impresiona, y consigue que nos sintamos empequeñecidos y casi aniquilados:

54. Hay que tener en cuenta que las Ideas de razón, entre las que se incluye la de Dios, no son esquematizables, lo que quiere decir que no es posible que formemos imágenes de ellas. Eso ha conducido a decir que no es posible hacer una esquematización "sublime" de la naturaleza, y ni siquiera un esquema de la naturaleza considerada como sublime, puesto que lo sublime es de imposible representación-esquematización. Sin embargo, Kant no desecha la posibilidad de esquematizar en cierto modo lo suprasensible y por eso en la Crítica del juicio, desde un punto de vista estético, no epistemológico, encuentra una solución: exponer lo suprasensible de forma indirecta o analógica a través de lo que se denomina simbolo. Véase Francisca Pérez Carreño, "Imagen y esquema en la Crítica del juicio", en José Luis Villacañas et al., Estudios sobre la Crítica del juicio, Madrid, Visor, I990. 
$Y$, pese a que una consideración de sus restantes atributos puede aliviar de algún modo nuestras aprensiones, ni nuestra convicción acerca de la justicia con la que los ejerce, ni la gracia con la que los tempera puede disipar por completo el terror que se desprende naturalmente de una fuerza a la que nada puede oponerse. Si nos regocijamos, nos regocijamos temblando e, incluso cuando nos estamos beneficiando, no podemos sino estremecernos ante un poder que puede conocer beneficios de tamaña importancia. 55

Dios, en cuanto imagen sensible y no en tanto concepto abstracto o intelectual, produce en nosotros temor, un sentimiento que, en la estética de Burke, se sintetiza todavía con el de lo sublime.

En el caso de Schiller, que sí diferencia, como Kant, lo terrorífico de lo sublime, Dios también provoca un terror capaz de convertirse ulteriormente en lo sublime; limita, además, nuestra seguridad y nos imposibilita para oponerle resistencia. Ante esa situación, sólo nos queda la seguridad moral, fundada en su justicia y en nuestra inocencia, que es la que consigue tornar lo terrorífico en sublime. Esta inocencia nos pone a salvo de la manifestación terrible del poder divino que contemplamos entonces sin espanto. ${ }^{56}$ Schiller matiza, en cualquier caso, que el sentimiento de seguridad no puede ser la causa de lo sublime, pues ni siquiera cuando se basa en fundamentos morales proporciona otra cosa que un principio de sosiego para la sensibilidad y la satisfacción del instinto de autoconservación. Y lo sublime no se funda en la satisfacción del instinto. Para que la idea de divinidad se torne dinámicamente sublime se hace, pues, necesario buscar el sentimiento de seguridad en nuestros principios fundamentales, no en la existencia:

Si como inteligencias nos sentimos independientes de los efectos de su poder, debe resultarnos indiferente lo que nos sucede como seres naturales. Únicamente cuando no puede aniquilar nuestra autonomía ni es capaz de forzar a la voluntad a obrar en contra de sus principios, nos percibimos independientes como seres racionales de su omnipotencia. 57

55. Edmund Burke, Indagación filosófica sobre el origen de nuestras ideas acerca de lo sublime y de lo bello, Menene Gras Balaguer (trad.), Madrid, Tecnos, I987, pp. 50-51.

56. Schiller, op. cit., pp. 85-86.

57. Ibidem, p. 86. 
Así pues, la idea del poder de la divinidad es para Schiller dinámicamente sublime cuando le negamos cualquier posibilidad de "influir de modo natural sobre las decisiones de la voluntad". ${ }^{58}$

En cuanto a Kant, el infinito y lo sublime se relacionan, por supuesto, estrechamente, ${ }^{59}$ pero también lo hace con ellos el sentimiento que produce en el espíritu la divinidad. Todos ellos aparecen conectados porque el sentimiento de lo sublime enlaza la sensibilidad —y la imaginación — con la facultad superior al entendimiento, la razón, que es justamente la que pregunta de forma legítima por el principio del universo, por el destino, origen y duración del alma humana; en última instancia, por el creador de la naturaleza y del alma, es decir, por Dios.

En la Crítica del juicio se encuentran algunos párrafos donde el propio Kant conecta explícitamente lo sublime con la religión y que son, de hecho, los que Otto usa sin contextualizar. En ellos se explica, por ejemplo, que, en la religión, el único comportamiento conveniente en presencia de la divinidad es el prosternarse y rezar con la cabeza caída, con ademán y voz de contrición y de miedo. Pero esa actitud de sumisión respetuosa no es, sin embargo, sinónimo de sublimidad: "esa disposición de espíritu no está tampoco, ni con mucho, unida en sí, y necesariamente, con la idea de la sublimidad de una religión y de su objeto". ${ }^{60}$ Para Kant, como para Otto, sólo cuando el hombre tiene conciencia de sus sinceros sentimientos gratos hacia Dios (y no sólo de su miedo), sirven los efectos de la fuerza para despertarle la idea de la sublimidad permitiéndole elevarse por encima del temor. ${ }^{61}$ Este tipo de humildad religiosa, más

58. Idem.

59. "Sublime es, pues, la naturaleza en aquellos de sus fenómenos cuya intuición lleva consigo la idea de su infinitud." Kant, Crítica del juicio, op. cit., p. 26. "“Erhaben ist also die Natur in derjenigen ihrer Erscheinungen, deren Anschauung die Idee ihrer Unendlichkeit bei sich führt." Kant, Kritik der Urteilskraft, op. cit., p. 99.)

6o. Kant, Crítica del juicio, op. cit., p. 28. ("Allein diese Gemütsstimmung ist auch bei weitem nicht mir der Idee der Erhabenheit einer Religion und ihres Gegenstandes an sich und notwendig verbunden." Kant, Kritik der Urteilskraft, op. cit., p. I09.)

6I. "Sólo cuando tiene conciencia de sus sinceros sentimientos gratos a Dios sirven aquellos efectos de la fuerza para despertar en él la idea de la sublimidad de aquel ser, en cuanto reconoce en sí mismo una sublimidad de sus sentimientos, adecuada a la voluntad de aquél, y entonces se eleva por encima del temor ante aquellos efectos de la naturaleza, que no reconoce ya como los estrépitos de su cólera." Kant, Crítica del juicio, op. cit., p. 28. ("Nur alsdann, wenn er sich seiner aufrichtigen gottgefälligen Gesinnung bewusst ist, dienen jene Wirkungen der Macht, in ihm die Idee der Erhabenheit dieses Wesens zu erwecken, sofern er eine dessen Willen gemässe 
verdadera que la anterior — porque de ella ha desaparecido el miedo—, representa, pues, también en Kant, una disposición sublime del espíritu.

Lo sublime religioso, si podemos hablar así, constituye, pues, en la filosofía kantiana, un desenvolvimiento o avance desde un anterior sentimiento de miedo ante la magnificencia infinita de Dios. La humildad religiosa, lograda una vez que se supera ese temor, representaría para él — como para Otto — un signo de la más cabal sublimidad. La única diferencia que cabe apreciar entre ellos radica, de nuevo, en que esa sublimidad conforma, en el sistema kantiano, un sentimiento perfectamente racional. Otto critica su postura porque concede primacía a los aspectos irracionales de la religión. Sin embargo, a la vista del examen aquí realizado, ese interés por lo irracional, a la hora de comparar lo numinoso y lo sublime, tal vez resulte innecesario; si algo enseña la filosofía kantiana es que, para sentir lo sublime, incluso cuando procede de Dios, acudimos precisamente a la parte racional que nos singulariza, a la que eleva el alma y ensancha nuestro espíritu, recordándonos, a la vez, nuestra existencia como seres humanos en libertad; ésta, columna vertebral del sistema kantiano, no parece ser incompatible con una forma de entender la religión en que no tiene tanta cabida el misterio o la incomunicabilidad, la sumisión y el anonadamiento. Sencillamente, su religiosidad nos pone en presencia de un sentimiento de raíces estéticas que realza, en contraste, la parte más excelsa del ser humano, nos eleva sobre nuestra condición de criaturas, y enaltece, en definitiva, a la propia humanidad. \$s

Erhabenheit der Gesinnung bei sich selbst erkennt, und dadurch über die Furcht vor solchen Wirkungen der Natur, die er nicht als Ausbrüche seines Zornes ansieht, erhoben Wird.” Kant, Kritik der Urteilskraft, op. cit., p. I Iо.) 